\title{
Food Security: Peasant Farmers Role in the Sawla Tuna-Kalba District of Ghana
}

\author{
Chukwunyere "Chuks" Ugochukwu', Ph.D. \\ Saint Cloud State University \\ Department of Geography and Planning \\ St Cloud, MN, USA \\ Paul Baidoo \\ University of Cape Coast \\ Faculty of Social Sciences \\ Department of Geography and Regional Planning \\ Cape Coast, Ghana
}

\begin{abstract}
A country and its people are food secured when production markets and social systems work in such a way that food consumption needs are always met (Mayer, 2001) Further, food security only exists when "all people at alltimes, have physical, social and economic access to sufficient, safe, and nutritious food that meets their dietary needs and food preferences for an active and healthy life" (Food and Agriculture Organization (FAO),2002).Concerns seek to address questions about: the role of farmers in ensuring food security in the district, the nature of food security in the district, the challenges encountered by farmers, and measures to forestall food insecurity in the district.
\end{abstract}

Keywords: Food Security, Rural development; Regional Planning; Agriculture; Community Development; Capacity Building; Globalization

\section{Introduction}

The history of agriculture dates back thousands of years and its development has been driven and defined greatly by different climates, cultures and technologies. Agriculture was the key implement in the rise of sedentary human civilization whereby farming or domesticated species created food surpluses that nurtured the development of civilization. Zimmerman (1972), defines agriculture to cover "those productive efforts by which man settled on the land, seeks to make use of the land and if possible, accelerate and improve upon the natural genetic or growth processes of the plant and animal life to the end that the processes will yield the vegetative and animal products needed or wanted by man."

It is worth mentioning that agriculture in Ghana is predominantly practiced on smallholder, family-operated farms using rudimentary technology to produce about $80 \%$ of her total agricultural output. It is estimated that about 2.74 million households operate a farm or keep livestock, and about 50.6\% of the Ghanaian labor force (4.2 million people), are directly engaged in agriculture (Population and Housing Census, 2000).In fact, farmers' contributions to the progress and development of the nation cannot be overestimated; hence they occupy a special place in society. Records at the Ghana's Statistical Services (GSS) indicate that agriculture, which remains the backbone of the economy, contributed about 30.2\% to Gross Domestic Product in 2010 as against 31.7\% in 2009. This placed the sector the second largest contributor to GDP. Despite this enormous contribution, its growth seems not to be significant perhaps, due to policies that favor other sectors of the economy over it, and urban over rural sectors. Such policies often reduce the profitability of agricultural activities and devastate the rural financial market, which in turn affects income distribution in agriculture and rural sectors (World Bank, 2000). Additional issues that discourages investment or engagement in agriculture on a broader scale includes market and commodity globalization; and Geo-politics on the regional, inter-national, multi-national, and global levels. Further, Bretton Woods institutions such as World Bank, International Monetary Fund (IMF), and World Trade Organization (WTO) conditionality's and tariff regimes to access financial assistance to improve infrastructure, development, and agriculture programs (Smallman, S and Brown, K., 2015). 
The fact that agriculture employs a chunk of the Ghanaian populace and that, peasant agriculture cuts throughout the country such that Sawla-Tuna-Kalba district in the northern region of the country has over $80 \%$ of its population engaged in peasant agriculture. The question is whether peasant farmers population scan meet their food needs considering that agriculture in the country is seriously grappling with the many challenges of modernizing local practices, as well as the forces of globalized agricultural market. In addition, farming in the district among majority of the people is constrained by limitations ofavailable sizeablelands for large scale farming considering that land is culturally inherited and often passed down from generation to generation. Thus, land acquisitions for large farms are limited to big deep pocketed individuals and farms. Further, operation of the peasant farm system reflects the cultural orientation of the people, which encourages polygamous marriages and large family sizes delivering the workers for the relatively large scale cultivation among the traditional households in the district (www.sawlatunakalbadistrict.com). The farming tools are mostly traditional ones such as hoes and cutlasses, typically used to cultivate the land togrow several food crops (mixed cropping) within a growing season on the same piece of land. This is done with the aim of harvesting enough food to supply their dietary needs for a growing season (covers planting to harvest of crops).

\section{Map of the study area}

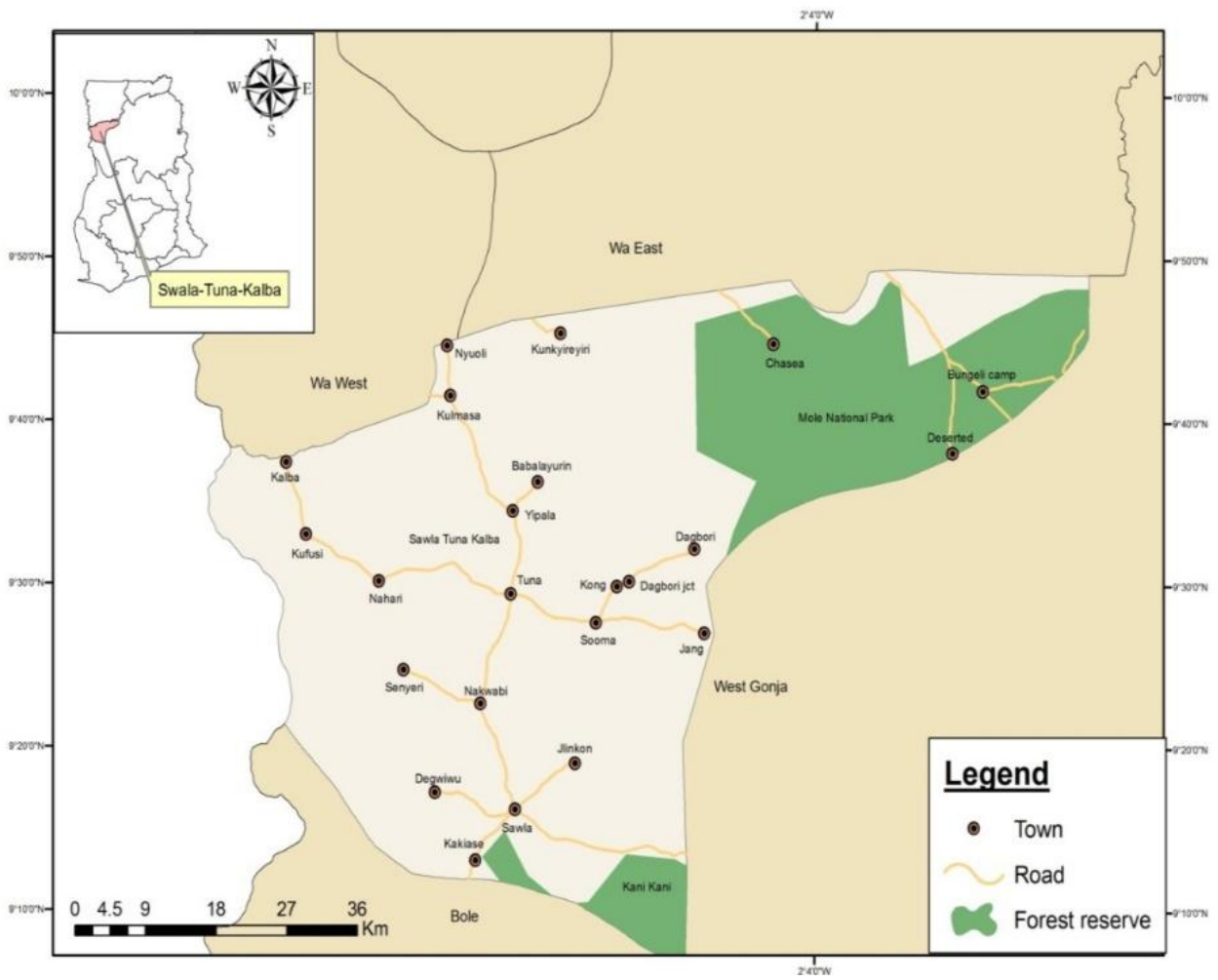

- Source: Cartographic Unit, UCC.

\section{Problem Statement}

The Ministry of Food and Agriculture (MOFA), to increase food production to ensure food security has over the years provided affordable, fast growing and high yielding seed varieties and agricultural inputs such as fertilizers, weedicides and insecticides, all at subsidized prices to help farmers throughout the country to increase food production.

Successive governments, since independence, have also tried policies that would close the development gab between the north and the south of the country. The Savannah Accelerated Development Authority (SADA) was created to lead achieving food security in Northern Ghana. SADA objective is primarily focused around food insecurity in the region, making the agricultural sector attractive to the people. Alhaji SeiduIddi, Chief Executive Officer of SADA, is of the opinion that food security holds the key to poverty reduction in the northern sector and the secretariat was prepared to partner research institutions to find lasting solutions to the problems of agriculture in the region (The Ghanaian Times, December 17, 2011,p3). 
For the purpose of boosting agriculture in the district and the region at large, the Northern Ghana Food Security Resilience Project (NGFSRP) co-funded by the European Union and the Adventist Development and Relief Agency (ADRA) UK was launched. NGFSRPtook several steps such as the provision of extension services, fast growing and resistant food crop varieties and fertilizers to selected farmers at subsidized cost.

The 20-month project which began in January 2010 was designed to reduce food insecurity for 10,000 vulnerable and resource-poor small-scale rural farme- households from 190 communities of which Sawla-Tuna-Kalba communities were included. Out of the 10,000 farmers, 3,976 (38.9\%) were women. The primary objective of the project is to increase resilience to soaring food prices. This was to be achieved by building beneficiary farmers' capacity in sustainable farming practices; providing agricultural inputs to complement these trainings and finally by creating market linkages between producers and potential buyers. Collectively, over 59,680 farmers in various parts of the Northern Region of which Sawla-Tuna-Kalba district is part of, and other communities in the Upper West region benefited from training sessions comprising group formation, dynamics and development; improved crop production techniques; harvesting and post harvesting technologies; business plan preparation and group constitution development; crop value chain and farming as a business (Northern Ghana Food Security Resilience Project, 2011).

Overall, a population that is dominantly agriculture would produce enough to feed itself and have surpluses when the necessary conditions such as credit facilities, mechanization, resistant and fast-growing food crop varieties and extension services are available, (Vaconcella, 1979).Addressing the Chiefs and People of Tuna Traditional area about "Integrating New and Modern Technology into the Traditional Farming Practices" ensuring food availability and sufficiency, the branch coordinator of ADRA Ghana Ltd, (Sawla), Mr. Reuben Seidu Lankoor said "Sawla-Tuna-Kalba District is predominantly agricultural with about $85 \%$ of the District economically active population (18-54years) involved in various farming activities (www.sawladistrict.info.gh). Produce such as yam, maize, groundnuts, rice, millet, cowpea, bambara beans and soya beans are common to majority of the farming communities. This also highlights how diversified the food crop produced. It will be enough to meet local need and export the surplus to other regions of the country. What isseen in common markets are imported maize from Techiman and other places of the country as well as rice, beans, groundnut and the like, especially, around the months of June to September" justifying the incidence of rising food insecurity amongst households coupled with the persistent increase in food prices, which must come to a halt (www.sawladistricts.gov.gh).

Concerns seek to address questions about: the role of farmers in ensuring food security in the district, the nature of food security in the district, the challenges encountered by farmers, and measures to forestall food insecurity in the district.

\section{Objectives of the study}

To assess the role of peasant farmers in ensuring food security in the district is the primary objective of the study, and in doing so:

1. Assess the activities of peasant farmers aimed at ensuring food security

2. Assess the food security situation in the Sawla-Tuna-Kalba District

3. Identify the challenges to peasant farmers in providing food security to the district

4. Examine ways increased food production can be enhanced in the district.

\section{Rational for the study}

The study significance is to assess the role of peasant farmers in ensuring food security in the district. It is expected that the study will generate further questions as well as serve as reference material for related work. Further, inform policy makers, Non-Governmental Organizations (NGOs), and other stakeholders about the livelihood of the people in the district and food security.

\section{Review of the Literature}

The review involves both theoretical and empirical and the items reviewed were food security concept, pillars, benefits, measurement, improvement and barriers.

\section{Concept of Food Security}

A country and its people are food secured when production markets and social systems work in such a way that food consumption needs are always met (Mayer, 2001) 
Further, food security only exists when "all people at all-times, have physical, social and economic access to sufficient, safe, and nutritious food that meets their dietary needs and food preferences for an active and healthy life" (Food and Agriculture Organization (FAO),2002). Food Security has evolved in the last thirty years to reflect changes in official policy thinking. Clay, (2002) \& Heidhues et.al, (2004).

Food Conference (1974) defined Food Security in terms of food supply-assuring the availability and price stability of basic food stuffs at the international and national level. "Availability at all times of adequate world food supplies of basic food stuffs to sustain a steady expansion of food consumption and to offset fluctuations in production and prices of economic access to the basic food that they need" (Food and Agricultural Organization, 1983). The definition was revised to include the individual and household level, in addition to the regional and national level of aggregation in food security analysis. In 1986, the highly influential World Bank Report on Poverty and Hunger (World Bank, 1986) focused on temporal dynamics of Food Security (Clay, 2002). The report introduced the distinction between chronic food insecurity associated with problems of continuing or structural poverty and low incomes and transitory food insecurity which involved periods of intensified pressure caused by natural disasters, economic collapse or conflict.

International Food and Development Agency explained further that, when a household is persistently unable to meet the food needs of its members over a long period of time marked by continuous, temporary bits of good and bad moments, then there is a long-term problem, and is known as chronic food insecurity (Clay, 2002). The shortterm problem may afflict any household, regardless of whether it has a chronic problem or not. Crop failure, seasonal scarcities, and temporary unemployment among the productive members of the household or perhaps an emergency need for large cash expenditure may all be reasons for the sudden reduction of a household's access to food below the nutritionally adequate level, and is known as transitory food insecurity (Clay, 2002).The widely accepted World Food Summit, Accra, (1996) definition reinforces the multi-dimensional nature of food security and includes food access, availability, food use and stability. It has enabled policy responses focused on the promotion and on recovery of livelihood options, initially made popular by academic such as Chambers and Conway (1992).

Food Security by a household always means access by all members to enough food for an active, healthy life. Food Security include at a minimum:

- The ready availability of nutritionally adequate and safe foods.

- An assured ability to acquire acceptable foods in socially acceptable ways (that is without resorting to emergency food supplies, scavenging, stealing, or other coping strategies (United States Development Agency, 2008).

The overall availability of food is not a problem, rather the problem often is poor distribution and a lack of purchasing power (United Nation Development Programm, 1994). Therefore, since individuals do not have the means, they do not have the purchasing power and cannot obtain nutritious food. Community Food Security exists when all community residents obtain a safe, culturally, acceptable, nutritionally adequate diet through a sustainable food system that maximizes community self-reliance and social justice (Hamm and Bellows, 2003).The Ministry of Food and Agriculture(MoFA) defines food Security as "good quality nutritious food, hygienically prepared, packaged and attractively presented, available in sufficient quantities all year round and located at appropriate places at affordable prices" (MoFA, 2008). Barring any unusual happenings, therefore, food must be produced in abundance and should be accessible all year round to all and sundry at affordable prices. Food Security is achieved when the poor and vulnerable parties usually women, children and those living in marginal areas of the society, have secure access to the food they want. Food security is achieved when equitable growth ensures that these groups of people have sustainable livelihoods (www.gbcghananews, 2009).

\section{Measurement of Food Security}

Accurate measurement of household food security can help public officials, policy makers, service providers, and community groups assess the need for assistance, judge the effectiveness of existing programs designed to help such households, and intensify efforts aimed at population subgroups with unusually severe levels of food security (Bickel, et. al., 2000)

Food Security - Access to all people at all times to enough food for an active, healthy life includes at a minimum:

- The ready availability of nutritionally adequate and safe foods, and 
- An assured ability to acquire acceptable foods in socially acceptable ways (for example without resorting to emergency food supplies, scavenging, stealing or other coping strategies (Bickel et. Al).

Food insecurity - limited or uncertain availability of nutritionally adequate and safe foods or limited or uncertain ability to acquire acceptable food in socially ways.

Hunger- the uneasy or painful sensation caused by a lack of food. The recurrent and involuntary lack of access to food. Hunger may produce malnutrition over time. Hunger is a potential although not necessary consequence of food insecurity. Food security (F.S.) and hunger as the terms are used here, are conditions resulting from financial constrain.

Bickel et, al (2000) also explains the three levels of food severity:

- Food secure: households with no or minimal indication of food insecurity.

- Food insecure without hunger: households concerned about inadequate resources to buy enough food who have adjusted by decreasing the quality of their family diet with little or no reduction in household food intake.

- Food insecure with hunger: Food insecure households in which one or more members (mainly adults) have decreased the amount of food they consume to the extent that they have repeatedly experienced the physical sensation of hunger.

The full range of food insecurity and hunger cannot be captured by any single indicator. Instead a household's level of food insecurity or hunger can be determined by obtaining information on a variety of specific conditions, expertise and members that serve as indicator of the varying degrees of severity of the condition. Some indicators include such as:

- Anxiety that the household food budget or food supply may be insufficient to meet basic needs

- The experience of running out of food, without money to obtain more

- Perception by the respondent that the food eaten by household members was inadequate in quality and quantity

- Adjustment to normal food use, substituting fewer and cheaper foods than unusual

- Instances of reduced food intake by adults in the household, or consequences of reduced intake such as the physical sensation of hunger or loss of weight

- Instances of reduced food intake for children in the household (Guide to measuring Household Food Security, 2000)

The Federal Food Security measures the food security status of households as groups and not necessarily particular household members. In general, conditions of food insecurity are believed to affect all household members, although not necessarily in the same way. By contrast, hunger is a uniquely individual phenomenon, whereby some members of the household may be hungry while others are not. Consequently, when the measure classifies a household into the more severe level of food insecurity with hunger, it means that at least some member or members of the household are experiencing hunger due to insufficiency of household resources, but not necessarily all the members. These are households with evidence to indicate that some members have been hungry due to lack of resources at least sometime during the last 12 months, but not necessarily all the members and not necessarily in all, or over most months (Bickel, et. Al, 2000)

\section{Pillars of Food Security}

In many counties, health problems related to dietary access are an ever-increasing threat. In fact, malnutrition and food borne diarrhea are becoming double burden. Hence food security is built on three pillars(World Health Organization, 2011).

- Food availability: enough quantities of food available on a consistent basis

- Food access: having enough resources to obtain appropriate foods for a nutritious diet.

- Food use: appropriate use based on knowledge of basic nutrition and care, as well as adequate water and sanitation

Making foods available and accessible to a population require the collaborative efforts of individuals, communities, stakeholders, NGOs and government, as well as, International agencies, the greatest of which are embedded on the individual and the state (Stalin, 2008). 
Increasing food availability requires the implementation of favorable policies on the provision of credit facilities, adaptation to the new and modern technology, coupled with the provision of fertilizers, improved and resistant crop varieties at subsidized prices, as well as, good governance to create a serene political environment for the individual farmers and the population at large. The unfavorable trade policies of the world market contribute greatly to the falling standards of agriculture production in most developing countries, and until governments of developing countries realize this and take steps to address the situation, their survival in centuries to come in terms of food needs, would be determined by external agencies (Smallman andBrown,2015).

Emphasis on cash crop production at the expense of food crop in most African countries and for that matter, Ghana, is a serious policy defect that needs revision. Successive governments in Ghana have made efforts to increase food production, notable of which is the Operation Feed Yourself by the Acheampong's government, which was hailed as the most successful amongst all agricultural policies in the country (Duodu, 2004). The policy was seen as such because of the food sufficiency levels that was evident in backyard gardening, provision of seedlings to farmers, one-acre demonstration farms, special maize program, and massive support by the local government.

\section{Benefit of Food Security}

Food Security can provide most of a household's total yearly vegetable needs, including much of the household's nutritional requirement, for vitamins A, C and B complex as well as iron. Food production can operate at a forprofit farm scale, producing high quality fresh foods (including protein-rich production). Producing their own food, their overall food consumption patterns and dietary knowledge improved (Patel, 1996).

The benefits of food production transcend the physical, mental and emotional health of the individual to leave lasting change on others and on the physical and social space of the community (Shoemaker and Diehl, 2002). It is associated with satisfying labor, physical and mental relaxation, socializing, and a means to produce food and beauty. Used well, gardening can be a key element in successful health intervention programs because it addresses simultaneously the physical, mental, spiritual, and social health of individuals and communities (Poppendieck, 1999).

\section{Barriers to Food Security}

Addressing the British All Party Parliament Group on Agriculture and Food for Development on "Linking Local Agriculture, Nutrition and Education: Innovations to improve Food Security," former president of Ghana, John Agyekum Kufour said that, "though most populations in Africa were engaged in farming, they still used 'centuries-old' method, which is difficult, back-breaking mainly on subsistence basis, and therefore did not attract the energetic and educated youth." (Daily Graphic, February 10, 2012). This highlights the grave lack of youth in agriculture evidenced by lack of modern technology for farming in the Sub-Region. "Africa alone of all the world's continents does not grow enough food to feed itself...... more than any continent, Africa needs solutions for its myriad of challenges in agriculture, nutrition and health" he added. Only viable agricultural policies covering such services as the provision of good roads linking farmlands to market centers, credit, improved and resistant crop verities, good marketing strategies, and modern technology in tillage of land can stimulate agricultural production on large scale basis thereby increasing farmers' income, and meet the food needs of people, thus help minimize the high levels of poverty among farmers and or the rural folks in the country. Worldwide, around 852 million people are chronically hungry due to extreme poverty, while up to 2 billion people are food insecure due to varying degrees of poverty (FAO, 2003). Eradicating hunger and poverty require an understanding of the ways these two injustices interconnect.

Hunger and the malnourishment that accompanies it prevents poor people from escaping poverty because it diminishes their ability to learn, work and care for themselves and their family members. Food insecurity exists when the people are undernourished as a result of physical unavailability of food, lack of social or economic access to adequate food, and or inadequate food utilization. Food insecure people are those individuals whose food intake falls below their minimum calorie requirements as well as those who exhibit physical symptoms caused by energy and nutrient deficiencies resulting from and inadequate or unbalanced diet or from the body's inability to use food effectively because of infection or disease. An alternative view will define the concept of food insecurity as referring only to the consequence of inadequate consumption of nutritious food, considering the physiological utilization of food by the body as being within the domain of nutrition and health. Malnourishment also leads to poor health hence individuals fail to provide for their families. 
If left unaddressed, hunger sets in motion an array of outcomes that perpetuate malnutrition, reduce the ability of adults to work and give birth to healthy children, and erode children's ability to learn and lead productive, healthy and happy lives. This truncation of human development undermines a community's and country's potential for economic development for generations yet unborn. (Von Braun et. al, 2004). What could possibly endanger food security are potential instability, factors such as adverse weather, drought and desertification, impoverished soils, wrong application of pesticides, pests and diseases, as well as inadequate knowledge of post- harvest handling and storage of crops, and rainstorms or too much rain that tend to destroy rather than favor crops production.

A more serious threat to food security lies in the fact that thousands of young people who could contribute significantly to food production are migrating in their numbers to the cities or urban areas in search of better invisible jobs. Subsequently, they leave behind old and frail men and women who might not be able to feed themselves properly, let alone provide food for the entire population at an assured pace. According to FAO (1992) report, "young people in rural areas could reach their potential without migrating to the cities if there are coordinated and concerted efforts to their educational, economic, medical, political, social and cultural needs."The report further explained some factors that cause food insecurity in details such as world food prices, poverty, healthy water and environment, gender equity, disaster, and conflict,mass urbanization, and trade.

\section{World Food Prices}

When the FAO Cereal Price Index doubled in the year 2008, food security became a global crisis. As the world's poorest households spend 60-100\% of their incomes on food, they have no mechanism to cope with rising prices other than to reduce the volume or nutritional quality of their consumption. The crises reintroduced hunger to borderline rural households, created a new class of urban poor and led to food riots in 30 countries.

\section{Poverty}

The poor lack access to sufficient resources to produce or buy food. Poor farmers may have very small farms, use less effective farming techniques, and or be unable to afford fertilizers and labor, including time saving equipment, all of which limit food production possibilities. Often, they cannot grow enough food for themselves, let alone generate income by selling excess to others. Without economic resources and political voice, poor farmers may be forced to less productive land possibly causing further environmental deterioration. Addressing poverty is critical to ensuring that all people have enough food.

\section{Health}

Without sufficient calories and nutrients, the body slows down, making it difficult to undertake the work needed to produce food. Without good health, the body is also less able to make use of the food that is available. A hungry mother will give birth to an underweight baby, who then faces a future of stunted growth, frequent illness, and learning disabilities and reduced resistance to diseases. Contaminated food and water can cause illness, nutrient loss and often death in children.

The HIV/AIDS pandemic have reduced food production in many affected countries as productive adults become ill or die. Lacking the labor, resources and know how to grow staple and commercial crops, many households have shifted to cultivating survival food or even leaving their fields, further reducing their supply. Addressing health issues will improve utilization and availability of food.

\section{Water and Environment}

Food production requires massive amounts of water. It takes one cubic meter (1000 liters) of water to produce one kilogram of wheat and 3000 liters of water to produce one kilogram of rice. Producing sufficient food is directly related to having sufficient water. Irrigation can ensure an adequate and reliable supply of water which increases yields of crops by $100-400 \%$. Although only $17 \%$ of global crop land is irrigated, and the $17 \%$ produces $40 \%$ of the world's food. Increasing irrigation efficiency and limiting environmental damage through de-salinization or reduced soil fertility are important for ongoing food availability. Where water is scarce and has been called 'virtual water', that is importing food from countries with an abundance of water, this may be a more efficient use of scarce resources.

\section{Gender Equity}

Women play a vital role in providing food and nutrition for their families through their roles as food producers, processors, traders and income earners. Yet women's lower social and economic status limits their access to education, training, land ownership, decision making and credit. 
Food utilization can be enhanced by improving women's knowledge of nutrition and food safety, and prevention of illnesses. Increasing women's involvement in decision making and their access to land and credit will in turn improve food security.

\section{Disasters}

Droughts, floods, cyclones and pests can quickly wipe out large quantities of food as it grows or when it is in storage for later uses. Likewise, seeds can be destroyed by such environmental dangers.

\section{Population and Urbanization}

Population growth increases demand for food. With most productive lands already in use, there is pressure for the land to become more productive. Poor harvest and higher costs lead to the migration of most rural farmers to cities in search of work. Expanding cities sprawl across productive land, pushing food production further and further away from consumers. This increases the cost of all the activities associated with producing and transporting food and decreases the food security of the poor in cities.

\section{Trade}

Many poor countries can produce staples more cheaply than rich nations. However, barriers to trade, such as distance from markets, quarantine regulations, and tariffs make it difficult for them to compete in export markets against highly subsidized farmers in rich countries (Smallman, S andBrown, K.2015). This deprives poor farmers of income and entire countries of their agricultural base because they need to develop other sectors of the economy. In addition, trade imbalances prevent poor countries from importing agricultural products that could enhance their food security.

\section{Measures to improve food security}

Specific programs to improve food security for those in need include:

- Helping people improve their farms and productivity

- Constructing food stores and improving roads so that food can be moved to where it is needed, or where it can be sold

- Promoting national rule to encourage economic growth and poverty reduction

- Improving the status of women and girls so they may have more control over the areas in which they have traditionally been involved and can access new areas

- Ensuring that people, especially children, receive food in emergency situations

- Promoting rural development, including sustainable agriculture, fishery, and forestry production and management of natural resources

- Preparing for disasters and emergencies to meetemergency food requirements in ways that encourage recovery and rehabilitation

USAID propose several key steps to increasing agricultural productivity that in turn is key to increasing rural income and reducing food insecurity. They include:

- Boosting agricultural science and technology. Current agricultural yields are insufficient to feed the growing population. Agricultural science and technology would help increase production and drive economic growth.

- Securing property rights and access to financial credit.

- Enhancing human capital through education and improved health.

- Conflict prevention and resolution mechanisms and democracy and good governance based on principles of accountability and transparently in public institutions and the rule of law. These are basic to reducing the number of vulnerable members of societies (USAID, 2008)

According to Martin Khor (2008), policies to obtain food security, developing countries must be allowed to provide adequate support to their agriculture sector and to have a realistic tariff policy to advance their agriculture, especially as developed countries' subsidies are continuing at a high rate. The developed countries should quickly reduce their actual levels of subsidy. The agriculture policy paradigm in developing countries must be allowed to change. Countries should have the policy space to expand public expenditure on agriculture. Government in developing countries should place high priority on expanding local food production. 
Accompanying measures and polices should thus be put in place, the countries should be allowed to calibrate their agricultural tariffs in such a way as to ensure that the local products can be competitive, and the farmers' livelihoods and incomes are sustained, and national food security is assured.

\section{Food Security in Ghana}

Lured into the business of exporting exotic fresh foods to Europe, Ghana has neglected its own food security situation. The lack of investment in storage, irrigation and credit results in low yields for the small- scale subsistence farms of which large proportion of the population depends. Land tenure is weak and there has been insufficient protection against imports from countries with generous subsidy regimes. The consequence is that Ghana must import a significant proportion of its staple rice and grains, leaving the country exposed to the spiral in world prices during 2008. Furthermore, it is difficult to secure credit from both formal and informal institutions, hence a burden to households already spending greater portion of their income on food. This resulted in the government abandoning her non-interventionist strategy in agriculture. Today, the sector is stimulated with subsidized seeds and fertilizers along with free tractor service to some farmers (http://www.oneworld.com, 2008).

\section{Adventist Development and Relief Agency: Ghana and food security intervention in northern Ghana}

The 20-month project which began in January 2010 was designed to reduce food insecurity for 10,000 vulnerable and resource-poor small-scale rural farmer households from 190 communities of which Sawla-Tuna-Kalba communities were part. Of these 10,000 farmers 3,976 (38.9\%) were women. The registered farmers were grouped into 303 farmer associations to facilitate their operation. The benefits among others include the following:

\section{Provision of resistant seed varieties and other inputs}

Over the 20-month implementation period, the project achieved the following: Farmers were supported with 92 tons of seed maize, 9.3 tons of seed groundnut, $45 \mathrm{~kg}$ of soybean seeds, 1,224 tons of NPK fertilizer and 545 tons of sulphate of ammonia fertilizer. Farmers were able to increase their yields 3 to4-fold due to agricultural input support, capacity building activities in crop production, and farmer group organization. Minimal storage losses were recorded, and household food insecurity was reduced from 3 to 4 months to one month.

\section{Training of farmers on cultural practices}

Training refers to the process of acquiring skills: the process of teaching or learning a skill or job (Microsoft Student Encarta, 2009). Cultural practices on the other hand refer to those practices that are carried out in the farm before and after transplanting. Collectively over 59,680 farmers in various parts of the Northern Region and other parts of the upper west region benefited from training sessions including group formation, dynamics and development; improved crop production techniques; harvesting and post harvesting technologies; business plan preparation and group constitution development; crop value chain and farming as a business. Farmers were trained on correct storage of their produce in order to maintain high produce quality and meet buyer/market requirements.

The Volunteers were taken through topics such as: volunteerism techniques, importance of agriculture extension delivery, adult education methodologies, soil fertility improvement and crop production techniques. Each of the trainees received a pair of Wellington boots, cutlass, crop production manuals and a set of stationery for record keeping.

\section{Provision of Market for Farmer's Produce}

Market is a medium through which goods and services are traded (bought and sold). By linking farmer groups to specific buyers, targeted farmers received higher prices for their produce compared to prevailing market prices at the time of sale. For example, a maxi-bag of maize sold at Tamale and surrounding markets fetched between $\mathrm{GH} \notin 34.00$ and $\mathrm{GH} \notin 36.00$. Project farmers received a minimum of $\mathrm{GH} \phi 40.00$ per maxi-bag for their maize. A revolving fund was created. In the first year, a total of $\mathrm{GH} \phi 464,897.00$ was collected to buy inputs for the 2010/2011 agricultural cycle (Northern Ghana Food Security Resilience Project, April 2011).

\section{Conclusions and Recommendations}

The study showed the following findings:

- Over fifty percent of the respondents or farmers in the district had no formal education, large families with households an average seven children. 
- Source of information on planting time, methods and technique was largely reliant on respondents' own knowledge and experience. In addition, respondents lacked knowledge on where and how to secure loans.

- Inaccessible roads linking farmlands to villages and market centers was another finding of the study.

- A number of the population relied on wells for drinking water, which unfortunately do not provide them water throughout the year, especially during the dry season.In addition, rainfall which respondents largely depended on for cultivation was an obstacle to production during the period of the study. Having stated that they started cultivation around the periods of March and April, most farms that were meant for either maize or millet planting at the time of the investigation had no seedlings or plants due to late rainfall and the inconsistency of the rainfall pattern (see snapshot A).

\section{Recommendations}

Considering the challenges that farmers in the district face, the following are recommendations:

- Information should be made readily available to farmers on the methods and times of planting, as well as the channels through which they can access credit or loans to enhance increased productivity.

- The government through the district assembly should provide piped borne water to farmers that rely on well as their source of drinking water, as well as expand water supply to meet the needs of farmers that already use piped borne water. Further, a policy on water irrigation should be given serious attention by government to enable farmers produce food crops during the dry season.

- People should also be educated on the need to control number of birthsin order to control the number of people in a household.

\section{References}

Chambers and Conway (1992) Changing Policy Concepts of Food Security: FAO Agricultural and Development Economics Division: Retrieved from: http://www.fao.org/es/esa/Ec-FAO on 12/02/12

Clay, 2002; Heidhuestal, 2004. Changing Policy Concepts of Food Security FAO Agricultural and Development Economics Division: http://www.fao.org/es/esa/

Clay, E. 2002. Food Security: Concepts and Measurement, Paper for FAO Expert Consultation on Trade and Food Security: Conceptualizing the Linkages Rome, 11-12 July 2002. Published as chapter 2 of Trade Reforms and Food Security

Dickson K.B and Benneh G. (1988), A New Geography of Ghana. London Group (FE) Ltd, Legon, Accra.

Duodu K. (2004), The Revisiting The Agriculture Policies of Ghana, Ghana University Press, Accra.

Ec-FAO Food Security Program: http://www.foodsecinfoaction.org/

Ellis, F. (1992), Agricultural Policies in Some Developing Countries. Cambridge; Cambridge University Press entitlement. New York: Penguin Books.

FAO (1983), Financial Market Fragmentation and Reforms in Sub-Sahara Africa: Atehnical ompendium in FAO agricultural service, Bulletin.

FAO (91992 report) Journal in Agriculture Production Vol.7.no 1

Fernandez J. (2012), How To Increase Food Production www.voanews.com/policy/editorials/africa/Fernandezon-how-to- increase-food-production

Food Security in the United States: Measuring Household Food Security. USDA. (www.ers.usad.gov/briefing/food security//measurement.hmt)

Food Security Program: http://www.foodsecinfoaction.org/

Food Security, nutrition and the Millennium Development Goals (Annual Report Essay) Washington, D.C: International Food Policy Research Institute (IFPRI).

Hamm J \& Bellows (2003). Journal of Nutrition Education and Behavior, 35 (1):37-43.

Innovations to Improve Food security, Daily Graphic, Friday, February 10, 2012, Pp.16.

International Food Programme and Research Institute (2000), international food policy research institute conference report; food safety and security improvement in 2020 pg. 22.

K A Haizel, (1994), An Inaugural lecture delivered at the University of Cape Coast, Cape Coast on 9th March 1987, Ghana University Press, Accra.

Martin Khor (2008), Rising Prices Reinforced Need for Food Security Policies, 
ISIS Report 15/07/08. Impact of trade Liberalization on Agriculture in Developing Countries: the experience of Ghana. TWN, Penang, 2008.

Microsoft Student Encarta, 2009, Microsoft student corporations, (2008-2009).

MoFA, FASDEP (2008) Food and Agriculture Sector Development Policies Report on Improving Food Security. Meaning of Food and Agriculture

National Development Planning Commission (2003). Ghana Poverty Reduction Strategy (GPRS) Paper- An Agenda for Growth and Prosperity. Accra, Ghana. P.3.

Patel, Iswarbhai C (1996), "Rudgers Urban Gardening: a case study in urban agriculture”. Journal of agriculture and food information. 3(3):35-46

Poppendieck, J. (1999). Sweet charity: Emergency food and the end of Shoemaker, Candice A. and Elezabeth RM

Diehl (eds). 2002. Interaction by design: Bringing animals and plants together for health and well-being: an international symposium. Iowa: Iowa state press. Stanford University Press, Stanford, California

Smallman, S andBrown, K. (2015). Introduction to International and Global Studies, 2nd edition, University of North Carolina Press

Stalin M, (2008). Population, Agriculture and Food Security, Ghana University Press, Accra.

The Ministry of Health Population and Housing Census, (2004). (http://sawla.ghanadistricts.gov.gh/-Sawla-TunaKalba)

The National Poverty Reduction Programme- NPRP. (1999). Poverty Reduction News (NKOSOO). May Edition. Volume 1. Accra. Skyline Print Advertisement. Pp. 1-6.

The Role of SADA in Food Security", The Ghanaian Times, December 17, 2011. Pp 3.

Yunus Muhammed. Noble lecture, Oslo, December 10, 2006. The noble foundation,2006.www.globaled ucatio n.ed ua.edu.au/globaled/go.

Zellor,M.Schirieder, G. Von Brown, J and Heidhues, F. (1997), Rural Finance for Food Security for the Poor: implication for research and policy. Food Policy Review, No.4, Washington D C; International Food Policy Research Institute.

Zimmermann, W. E. (1972), World Resources and Industries, 3rd edition, Harper and Row Incorporated 49. 33rd Street, New York. 